\title{
Incidence of Hypertension and Associated Cardiovascular and Metabolic Status in a Group of Official Population of Bangladesh
}

\author{
S.M. Rezaul Irfan ${ }^{1}$, AMB Safdar², Md. Zahid Alam³ ${ }^{3}$ Samira Humaira Habib ${ }^{4}$, Rashedul Islam ${ }^{5}$, Mohammad \\ Shakhawat Hossain ${ }^{6}$, Shabnam Jahan Hoque ${ }^{7}$, A.K.M. Mohibullah ${ }^{8}$
}

\begin{abstract}
:
Hypertension is one and the major non communicable diseases in the world and contributing significantly to the burden of cardiovascular diseases, stroke, kidney failure and premature death. The prevalence of hypertension in Bangladesh varies from $11-20 \%$ and $7 \%$ of the death in Bangladesh are due to hypertension related disease. Only $11 \%$ of the total cases of hypertension have effective control of blood pressure. Education, social awareness, income, access to physicians may be factors for less adherences to medications and effective control of the disease.

This study was undertaken in a group of population with average to good educational, social and economic background to see the incidence of the disease, its control and associated cardiovascular and metabolic status.
\end{abstract}

599 working officials above the age of $\mathbf{5 0}$ years were evaluated in BIRDEM General Hospital from January 2013 to December 2013 to see the incidences of hypertension, control of blood pressure and cardiac and metabolic status of the population. Total 308 patients in the study population had hypertension and 39 were newly detected. $68.8 \%$ of the patients with hypertension have effective control of blood pressure with medications and systolic hypertension was revealed in $8.7 \%$ cases. This might be due to increase awareness of the study population related to the educational, economic and social background and this plays an important role in effective control of the disease.

Keywords: Hypertension, Ischemic Heart Disease, Diabetes, Treadmill Test.
Introduction:

Hypertension is one of the major non-communicable diseases (NCDs) in the world, which significantly

1. Registrar, Department of Cardiology, BIRDEM General Hospital, Shahbag, Dhaka, Bangladesh.

2. Associate Professor, Department of Cardiology, BIRDEM General Hospital, Shahbag, Dhaka, Bangladesh.

3. Associate Professor, Department of Cardiology, BIRDEM General Hospital, Shahbag, Dhaka, Bangladesh.

4. Principal Research Officer, Health Economics Unit, Diabetic Association of Bangladesh

5. Registrar, Department of Neurology, BIRDEM General Hospital, Shahbag, Dhaka, Bangladesh.

6. Senior Medical Officer, Department of Cardiology, BIRDEM General Hospital, Shahbag, Dhaka, Bangladesh.

7. Junior Consultant, Department of Cardiology, BIRDEM General Hospital, Shahbag, Dhaka, Bangladesh.

8. Professor, Department of Cardiology, BIRDEM General Hospital, Shahbag, Dhaka, Bangladesh.

Address of Correspondence: Dr. S.M. Rezaul Irfan, Registrar, Department of Cardiology, BIRDEM General Hospital, Shahbag,

Dhaka, Bangladesh. E-mail: smrirfan@gmail.com contributes to the burden of cardiovascular diseases (CVDs), stroke, kidney failure, disability, and premature death. ${ }^{1-3}$ It is also identified as a global disease burden and is ranked third as a cause of disability-adjusted lifeyears (DALYs). ${ }^{4}$

According to World Health Organization (WHO), about 17 million deaths occur worldwide due to CVDs, of which hypertension alone accounts for 9.4 million deaths and $80 \%$ of the CVD-related deaths occurred in the developing countries. ${ }^{5-7}$ The global prevalence of hypertension is projected to increase from $26 \%$ in 2000 to $29.2 \%$ by 2025 which will be approximately $29 \%$ of the world's population. ${ }^{5}$ Although hypertension is more prevalent in developed countries its prevalence is increasing in the low and middle-income countries (LMIC). ${ }^{8,1}$ Countries in Asia, especially Southeast Asia, are having an increasing burden of hypertension including CVDs. ${ }^{9-11}$ According to WHO, hypertension has become a significant health concern in the Asian 
region, affecting more than $35 \%$ of the adult population. ${ }^{12}$ The two fast-growing economies, India, and China, have a huge burden of hypertension and are projected to proliferate by $2025 .{ }^{13}$ Bangladesh a developing country in South Asia has been experiencing an epidemiologic transition from communicable diseases to NCDs. ${ }^{14}$ The exact prevalence of HTN in Bangladesh is not known. Only a limited number of small-scale epidemiological studies are available. The prevalence of HTN was first reported in 1976, as $1.10 \%$. 15 One meta-analysis, a population-based study and a recently published survey found the prevalence of HTN as $11.3 \%, 18.6 \%$, and $20.1 \%$, respectively. ${ }^{16-18} 7 \%$ of deaths in Bangladesh are due to HTN-related diseases, which is equivalent to 9.6 million people of age 25 or above. ${ }^{19-20}$ Effective control of blood pressure is found in about $11 \%$ of total cases. ${ }^{20}$ This may be due to socioeconomic factors, including lack of awareness, high illiteracy rates, low income and difficulty in physician access. This has lead to late HTN detection and lack of compliance in HTN control through pharmacotherapy and lifestyle changes.

At the advent of the new millennium, we are really not aware of our real situation. Large-scale nation-wide survey and clinical research are needed to explore the different aspects of HTN in Bangladesh. This study is undertaken in a group of population having average to good educational, social and financial background to find out the incidence of hypertension along with the pattern of control and associated cardiovascular and metabolic status.

\section{Materials and Methods:}

This prospective observational study was conducted in BIRDEM General Hospital during a period of one year from January 2013 to December 2013. 599 Working officials of Bangladesh Bank with 50 years and above were studied during their yearly health checkup. An informed, voluntary written consent was obtained from each participant before enrolment. Detailed medical history and physical examination of the study population were entered in a data sheet. Patients with physical disability and known psychiatric illness were excluded.

The population group was screened for Hypertension according to JNC-7 (systolic blood pressure e" 140 $\mathrm{mmHg}$ and diastolic blood pressure e" $90 \mathrm{mmHg}$ or taking antihypertensive medications). During the course of the interview, two measurements of blood pressure on each study participant were measured with the mercury sphygmomanometer by auscultatory method.
Study participants were instructed to refrain from drinking any caffeinated beverage and from smoking half an hour preceding the check up. Both blood pressure measurements were obtained after the subject was rest for at least $5 \mathrm{~min}$ in a seated position. All blood pressure measurements were made on the left arm of each study subject, using a cuff of appropriate size at the level of the heart. The cuff pressure was inflated $30 \mathrm{mmHg}$ above the level at which the radial pulse disappeared, and then deflated slowly at the rate of about $2 \mathrm{~mm} \mathrm{Hg} / \mathrm{sec}$. The first (appearance) and the fifth (disappearance) Korotkoff sounds were recorded as indicative of the systolic (SBP) and the diastolic blood pressure (DBP) respectively. The average of two readings of SBP and DBP were used to describe the blood pressure of the participants. In case where the two readings differed by over $10 \mathrm{~mm}$ of $\mathrm{Hg}$, a third reading was obtained and the three measurements were averaged. The control of Blood Pressure of each individual was assessed by measuring the Blood Pressure on different settings.

Cardiac Status was evaluated by 12 Lead ECG, Exercise Tolerance Test and Colour Doppler Echocardiography. Ischemic heart disease was considered by the presence of T wave inversion and ST depression and Myocardial Infarction was considered by standard characteristics ST elevation and pathological $Q$ wave in corresponding leads representing a wall in 12 lead ECG. In ETT Bruce Protocol in majority and Modified Bruce in selected cases were carried out to evaluate Ischemic Heart Disease with standard excepted criteria.

Body Mass Index (BMI) of the study population was calculated by measuring the body height and weight with the subject standing motionless on the weighing scale, feet about $15 \mathrm{~cm}$ apart and the weight equally distributed on each leg. Subjects were instructed to wear minimum outwear (as culturally appropriate) and no footwear while their weight was being measured. This population group was also assessed for Metabolic Derangement by Fasting Blood Glucose, 2 Hours after Breakfast Blood Glucose, HbA1C and fasting Lipid Profile.

Data was analyzed for mean, percentage, standard deviation, chi square test, multiple correlation and multivariate analysis, by using SPSS-12 Windows. The t-test and chi square test was done for quantitative and qualitative analysis, respectively. P-value $<0.05$ was considered significant. 


\section{Results:}

Total 599 persons of above 50 year of age were studied from January 2013 to December 2013 in BIRDEM General Hospital. There were 533 male and 66 female. 297 $(49.6 \%)$ had the age below 55 years and 302 (30.4\%) had age above 55 years. The yearly income was bellow 50,000 taka in $70.78 \%$ subjects and $50,000-1,00,000$ taka in $28.71 \%$ person (Table-1).

Table-I

Age, Sex and Monthly income

\begin{tabular}{lccc}
\hline Variables & Parameters & No of Subjects & Percentage \\
\hline Age & $\leq 55$ & 297 & $49.6 \%$ \\
& $>55$ & 302 & $50.4 \%$ \\
Sex & Male & 533 & $89.0 \%$ \\
& Female & 66 & $11.0 \%$ \\
Monthly Income & $<50000$ & 424 & $70.78 \%$ \\
& $50000-100000$ & 172 & $28.71 \%$ \\
& $>100000$ & 3 & $0.5 \%$ \\
\hline
\end{tabular}

In this study population 308 (51.4\%) subjects were found to have Hypertension of which only $30(9.7 \%)$ were newly detected and 278 were previously known case of the hypertension. $68.8 \%$ were taking drug regularly and had effective control of Blood Pressure, $12.6 \%$ person had no control and only $8.7 \%$ had Systolic Hypertension (Table-2)

Table-II

Incidence of Hypertension.

\begin{tabular}{lc}
\hline Number of population with HTN & $308(51.3 \%)$ \\
Newly detected HTN & $30(9.7 \%)$ \\
Known case of HTN & $278(90.3 \%)$ \\
Controlled HTN & $212(68.8 \%)$ \\
Uncontrolled HTN & $39(12.6 \%)$ \\
Systolic HTN & $27(8.7 \%)$ \\
\hline
\end{tabular}

ECG evidence of Ischemic Heart Disease was found in 97 cases of which 17 patients had the evidence of old Myocardial Infarction (Table-3)

Table-III

ECG evidence of ischemic heart disease (97)

\begin{tabular}{lccc}
\hline ECG & With HTN & Without HTN & Total \\
\hline Myocardial Ischemia & 47 & 33 & 80 \\
Old MI & 15 & 02 & 17 \\
\hline
\end{tabular}

ETT were done in all patients. Symptom limited ETT were done in patients having ECG evidence of Myocardial Ischemia or Infarction. ETT was found positive in 208 out of 502 patients with negative ECG for Ischemic Heart
Disease. In ETT positive patients 120 had hypertension (Table-4).

Table-IV

Relation between ECG and ETT

\begin{tabular}{lllll}
\hline & & \multicolumn{2}{c}{ ECG } & Total \\
\cline { 3 - 4 } & & No & Yes & \\
\hline ETT & Negative & 350 & 41 & 391 \\
& Positive & 152 & 56 & 208 \\
\hline \multirow{2}{*}{ Total } & 502 & 97 & 599 \\
\hline
\end{tabular}

Transthoracic 2D Echocardiography with Color Doppler study were carried out in all patients and regional and global wall motion abnormality were seen in only 16 cases and diastolic dysfunction was present in 127 cases (Table-6).

Table-V

Echocardiography findings

\begin{tabular}{lc}
\hline Echocardiography & Total \\
\hline RWMA & 14 \\
GWMA & 02 \\
Diastolic Dysfunction & 127 \\
\hline
\end{tabular}

470 out of 599 study population had some form glycaemic abnormality. Diabetes Mellitus Type-2 were found in 238 (39.73\%), 113 (18.86\%) had IGT and 119 (19.86\%) had IFG. 129 patients has normal Glycaemic Status.

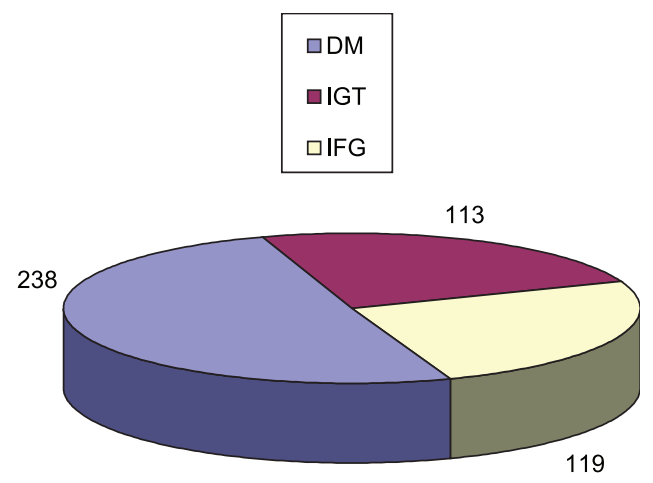

Fig-1: Pattern of glycemic status

It was revealed from BMI assessment that $48.4 \%$ of the study population was overweight and $12.8 \%$ had obesity of different grades (Table-6). 
Table-VI

Assessment of BMI

\begin{tabular}{llcc}
\hline Body Mass Index & Under Weight (<18.5) & 3 & $(0.5 \%)$ \\
& Normal (18.5-24.9) & 229 & $(38.2 \%)$ \\
& Over Weight (25-29.9) & 290 & $(48.4 \%)$ \\
& Obesity G-I (30-34.9) & 69 & $(11.5 \%)$ \\
& Obesity G-II (35-39.9) & 6 & $(1 \%)$ \\
Obesity G-III (40 and >) & 2 & $(0.3 \%)$ \\
\hline
\end{tabular}

All patients were evaluated for lipid status in fasting state. $326(54.4 \%)$ had raised LDL, 361 (61.3\%) low HDL and
289 (48.2\%) had raised Triglycerides. Status of the Lipid Profile in the study population is shown in the following bar diagram.

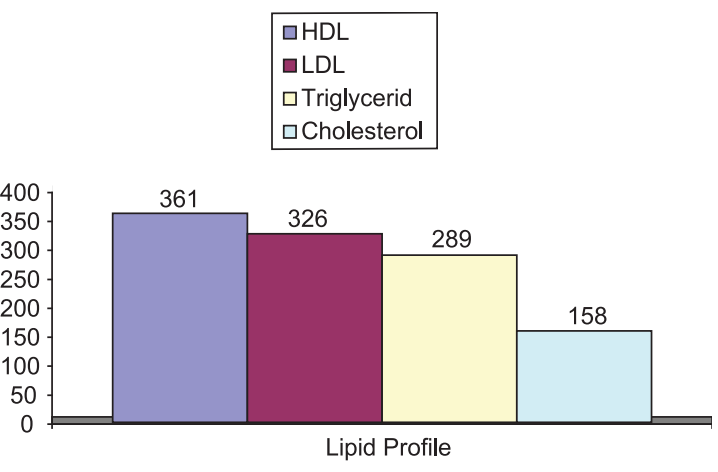

Fig.-2: Pattern of lipid profile

Table-VII

Risk Factors for IHD.

\begin{tabular}{lccc}
\hline & No $(\%)$ & P value & Odds Ratio (95\% Class Interval) \\
\hline Family H/o IHD positive & $29(4.9 \%)$ & .003 & $59.3 \%(.350-1.005)$ \\
Sex & $179(29.9 \%)$ & .006 & \\
Male (533) & $29(4.8 \%)$ & .001 & $15.5 \%(.923-2.603)$ \\
Female (66) & $102(17.0 \%)$ & .001 & $55.4 \%(.394-.781)$ \\
DM & & & \\
BMl & $42(7.0 \%)$ & .002 & \\
Overweight & $46(7.7 \%)$ & $\mathrm{HTN}$ & \\
Obesity-1 & $00(0.0 \%)$ & .506 & $(.430-.810)$ \\
Obesity- 2 & .003 & & $33.2 \%$ \\
123(20.5\%) & $50(8.4 \%)$ & .003 & $96.5 \%(.660-1.419)$ \\
Tobacco Consumption & & .198 & $12.5 \%(.895-1.755)$ \\
Lipids & $54(9.0 \%)$ & .002 & $102.4 \%(.730-1.436)$ \\
High Cholesterol & $108(18.0 \%)$ & .001 & $98.0 \%(.695-1.383)$ \\
High TG & $114(19.0 \%)$ & $(.442-.872)$ & \\
High LDL & $126(21.0 \%)$ & & \\
Low HDL & & & \\
\hline
\end{tabular}


In table 7 risk factors for IHD were analyzed in patients who had positive ETT. There were 208 (34.72\%) individuals who have evidence of IHD. Among them 179 $(29.9 \%)(p=.006)$ were Male and 29(4.8\%) $(p=.001)$ were Female. $102(17.0 \%)(p=.001)$ had Diabetes Mellitus and $123(20.5 \%)(p=.003)$ had Hypertension. Family history of IHD was positive among $29(4.9 \%)(p=.003)$ individuals of IHD and 50 (8.4\%) persons were smoker.

\section{Discussion:}

The health status and disease profile of human societies have historically been linked to the level of their economic and social development. With industrialization, the major causes of death and disability, in the more advanced societies, have shifted from a predominance of nutritional deficiencies and infectious diseases, to those classified as chronic diseases such as cardiovascular disease (CVD), cancer, and diabetes. High-fat diets, cigarette smoking, and sedentary lifestyles become more common along with continuous improvement of life expectancy. 21 Non-communicable diseases become predominate, with the highest mortality caused by atherosclerotic CVD, most frequently ischemic heart disease and athero-thrombotic stroke.

Hypertension is one of the most important preventable causes of premature morbidity and mortality and a major risk factor for ischemic and hemorrhagic stroke, myocardial infarction, heart failure, chronic kidney disease, cognitive decline and premature death. With ageing, systolic hypertension becomes a more significant problem, as a result of progressive stiffening and loss of compliance of larger arteries.

The high current burdens of non-communicable diseases (NCDs) are highlighted by the estimates provided by the Global Burden of Disease Study and in the World Health Report 1999, which indicate that these disorders together contributed to $59 \%$ of global mortality (31.7 million deaths) and $43 \%$ of the global burden of disease in 1998. ${ }^{22}$ Several NCDs such as cardiovascular diseases (CVD), cancers, diabetes, and chronic obstructive pulmonary disease are linked by common lifestyle determinants such as diet, physical activity, and tobacco consumption. 23 These four disorders together contribute to about $50 \%$ of global mortality. It is estimated that $30.9 \%$ of all deaths in 1998 , as well as $10.3 \%$ of the total disease related burden, in terms of disability adjusted life year loss (DALY loss) were attributable to CVD. ${ }^{20}$

In this context this observational study were undertaken in a specific population group of age 50 years and above having average to good educational background, social status and income to see the incidence of hypertension along with the state of control, number of medications needed and cardiovascular \& metabolic status of the patient.

In this study we had only 39 cases of newly detected hypertension and $68.8 \%$ had effective control contrary to the effective control of hypertension in only $11 \%$ of the total cases in Bangladesh. This might be due to their increase awareness which is related to their educational, social and economical background leading to good compliance to treatment. Systolic hypertension was revealed in $8.7 \%$ of the study population.

Out of 502 patients with normal ECG 152 (31.4\%) had positive ETT indicating myocardial ischemia and undoubtedly ETT is a good screening tool for IHD in this group of patients.

Of total 208 ETT positive patients 123 (62.1\%) had hypertension and the individual who had raised LDL cholesterol, raised total cholesterol and low HDL cholesterol are more likely to develop IHD (Table 7). Only $8.4 \%$ of the study population had the history of smoking or tobacco consumption. This may also be due to increase awareness in this group.

Almost $50 \%$ of the study populations were overweight and $39.9 \%$ had Diabetes Mellitus. $18.8 \%$ had IGT and $19.8 \%$ had IFG which are also important risk factors for macrovascular complication.

In conclusion we can draw an inference that education, social and economic status helps to increase the awareness of the patients to adhere to the medications and in other way contributes to the effective control of the disease.

This was a small study in specific group of population having particular social, educational and economic background. So this may not reflect the exact scenario of the disease. We are not really aware of the magnitude of these diseases in our population and large scale nationwide study is needed to find it out.

\section{References:}

1. Alwan A, World Health Organization. Global status report on noncommunicable diseases 2010. 2011.

2. He J, Whelton PK. Epidemiology and prevention of hypertension. Medical Clinics of North America. 1997;81(5):1077-1097. doi: 10.1016/S00257125(05)70568-X. 
3. Whelton PK. Epidemiology of hypertension. The Lancet. 1994;344(8915):101-106. doi: 10.1016/ S0140-6736(94)91285-8

4. Ezzati M, Lopez AD, Rodgers A, Vander Hoorn S, Murray CJL. Selected major risk factors and global and regional burden of disease. The Lancet. 2002;360(9343):1347-1360. doi: 10.1016/S01406736(02)11403-6.

5. Lim SS, Vos T, Flaxman AD, Danaei G, Shibuya K, Adair-Rohani $\mathrm{H}$, et al. A comparative risk assessment of burden of disease and injury attributable to 67 risk factors and risk factor clusters in 21 regions, 1990-2010: a systematic analysis for the Global Burden of Disease Study 2010. The Lancet. 2012;380(9859):2224-2260. doi: 10.1016/ S0140-6736(12)61766-8.

6. World Health Organization. A global brief on hypertension: silent killer, global public health crisis: World Health Day 2013. 2013.

7. Lozano R, Naghavi M, Foreman K, Lim S, Shibuya $\mathrm{K}$, Aboyans V, et al. Global and regional mortality from 235 causes of death for 20 age groups in 1990 and 2010: a systematic analysis for the Global Burden of Disease Study 2010. The Lancet. 2012;380(9859):2095-2128. doi: 10.1016/S01406736(12)61728-0.

8. Olives C, Myerson R, Mokdad AH, Murray CJL, Lim SS. Prevalence, awareness, treatment, and control of hypertension in United States counties, 20012009. PLoS One. 2013;8(4):e60308. doi: 10.1371/ journal.pone.0060308.

9. Singh RB, Suh IL, Singh VP, Chaithiraphan S, Laothavorn P, Sy RG, et al. Hypertension and stroke in Asia: prevalence, control and strategies in developing countries for prevention. J Hum Hypertens. 2000;14(10-11):749-764. doi: 10.1038/ sj.jhh.1001057.

10. Van Minh H, Byass P, Chuc NTK, Wall S. Gender differences in prevalence and socioeconomic determinants of hypertension: findings from the WHO STEPs survey in a rural community of Vietnam. J Hum Hypertens. 2005;20(2):109-115. doi: 10.1038/sj.jhh.1001942.

11. Hoang VM, Byass P, Dao LH, Nguyen TK, Wall S. Risk factors for chronic disease among rural Vietnamese adults and the association of these factors with sociodemographic variables: findings from the WHO STEPS survey in rural Vietnam, 2005. Prev Chronic Dis. 2007;4(2):A22-2.
12. Neupane D, McLachlan CS, Sharma R, Gyawali B, Khanal V, Mishra SR, et al. Prevalence of hypertension in member countries of South Asian Association for Regional Cooperation (SAARC): systematic review and meta-analysis. Medicine 2014;93(13):e74.

13. Kearney PM, Whelton M, Reynolds K, Muntner P, Whelton PK, He J. Global burden of hypertension: analysis of worldwide data. The Lancet. 2005;365(9455):217-223. doi: 10.1016/S01406736(05)70151-3.

14. Islam AK, Majumder AA. Hypertension in Bangladesh: a review. Indian Heart J. 2012;64(3):319-323. doi: 10.1016/S00194832(12)60096-0.

15. Malik A. Congenital and acquired heart diseases: (a survey of 7062 persons) Bangladesh Med Res Council Bull. 1976;2:115-119.

16. Zaman MM, Rouf MA. Prevalence of hypertension in a Bangladeshi adult population. J Hum Hypertens. 1999;13:547-549.

17. Zaman MM, Ahmed J, Chowdhury SR. Prevalence of ischemic heart disease in a rural population of Bangladesh. Indian Heart J. 2007;59:239-241.

18. Alamgir AKM, Ali SMK, Haque KMHSS. Extra salt intake as determinant of high blood pressure. Chest Heart J. 2009;33:127-133.

19. Lim SS, Vos T, Flaxman AD, Danaei G, Shibuya K, Adair-Rohani $H$, et al. A comparative risk assessment of burden of disease and injury attributable to 67 risk factors and risk factor clusters in 21 regions, 1990-2010: a systematic analysis for the Global Burden of Disease Study 2010. The Lancet. 2012;380(9859):2224-60.

20. World Health Organization. A global brief on hypertension: silent killer, global public health crisis: World Health Day 2013. 2013.

21. Krishnan A, Garg R, Kahandaliyanage A. Hypertension in the South East Asia region Regional Health Forum: WHO South East Asia Region 2013. 17(1): 7-14.

22. El-Saharty S, Ahsan KZ, Koehlmoos TLP, Engelgau MM. Tackling Noncommunicable Diseases in Bangladesh: Now is the Time. Washington DC: World Bank Publications, 2013:1-3.

23. Director General of Health Service, MOHFW. Strategic plan for surveillance and prevention of Non-communicable Disease in Bangladesh 20072011. 2007:1-46. 